\title{
Soluble aluminium in acidic soils: Principles and practicalities
}

\author{
G.S.P. Ritchie
}

\begin{abstract}
Our ability to predict toxic quantities of aluminium $(\mathrm{Al})$ in acidic soils is limited by our understanding of the interactions between different solid forms of $\mathrm{Al}$ in solution and our lack of knowledge of which form control soluble $\mathrm{Al}$. This review briefly considers each type of solid form of $\mathrm{Al}$, particularly from a kinetic point of view and discusses models that have been developed to predict release of $\mathrm{Al}$ from individual forms. More comprehensive models (i.e. more than one source or sink of Al) are then discussed as well as the interactions between different solid sources of Al.
\end{abstract}

\section{Introduction}

An understanding of the solubility and speciation of aluminium, $\mathrm{Al}$, in acidic soils is important in predicting the amount of toxic $\mathrm{Al}$ that is present in the soil. It is important, also, for predicting the amount of lime or other amendment needed to detoxify $\mathrm{Al}$, the frequency with which the soil has to be treated to maintain nontoxic quantities and the rate at which a soil will acidify in the absence of amelioration.

The forms of $\mathrm{Al}$ in soils (Fig. 1) and in surface waters have been reviewed extensively (Adams, 1984; Driscoll, 1989; Ritchie, 1989; Sposito, 1989a) but the interactions between the forms of $\mathrm{Al}$ are not so well established. Also, it is not clear how such reactions are affected by plant nutrient and $\mathrm{Al}$ uptake, water composition and movement through a soil profile, erosion of solid phase pools (e.g. wind erosion of organic matter) and by time. From the thermodynamic point of view, it may be argued that even though soluble $\mathrm{Al}$ may be instantaneously replenished from exchange sites, the ultimate source of $\mathrm{Al}$ is mineral dissolution. This may be correct in theory but its application to soils will depend on the time scale of interest and the kinetics of Al release from different solid phases (Ritchie, 1994). For example, Bloom et al. (1979) found that mineral dissolution did not replenish $\mathrm{Al}^{3+}$ (removed from the solution phase of a soil:liquid suspension by the previous addition of humus) even after $35 \mathrm{~d}$. One month may be an insignificant time period at the time scale of soil formation but represents approximately one third of the life span of annual crops including wheat and barley.

It is apparent that the dynamic nature of soils means that we cannot necessarily assume that the least soluble Al-containing mineral will be controlling the amount of $\mathrm{Al}^{3+}$ in solution and we have to appreciate that soils are essentially thermodynamically unstable. Despite this apparent complication, we still need to recall Einstein's (1979) assertion that, "A theory is the more impressive the greater the simplicity of its premises."

To understand the solubility and speciation of $\mathrm{Al}$, we need to find a balance between the extremes of oversimplification and complication. The balance is found by appreciating that the thermodynamic instability of $\mathrm{Al}$ compounds does not necessarily have to be a shortcoming and that the plant is the final arbiter. It is the plant's response to Al that decides which forms are toxic, not $\mathrm{Al}$ speciation.

The Law of Successive Reactions and the Kinetic Rule of Stages have been used in mineral dissolution studies to explain the type and sequence of compounds that precipitate from supersaturated $\mathrm{Al}$ solutions (Ritchie, 1994; Sposito, 1989b; Van Straten et al., 1984). These rules may be just as relevant to understanding the origin of soluble $\mathrm{Al}$ in soils, in the presence of multiple, unrelated sources of $\mathrm{Al}$, as they are relevant to predicting soluble $\mathrm{Al}$ control in pure systems where several minerals could exist. 


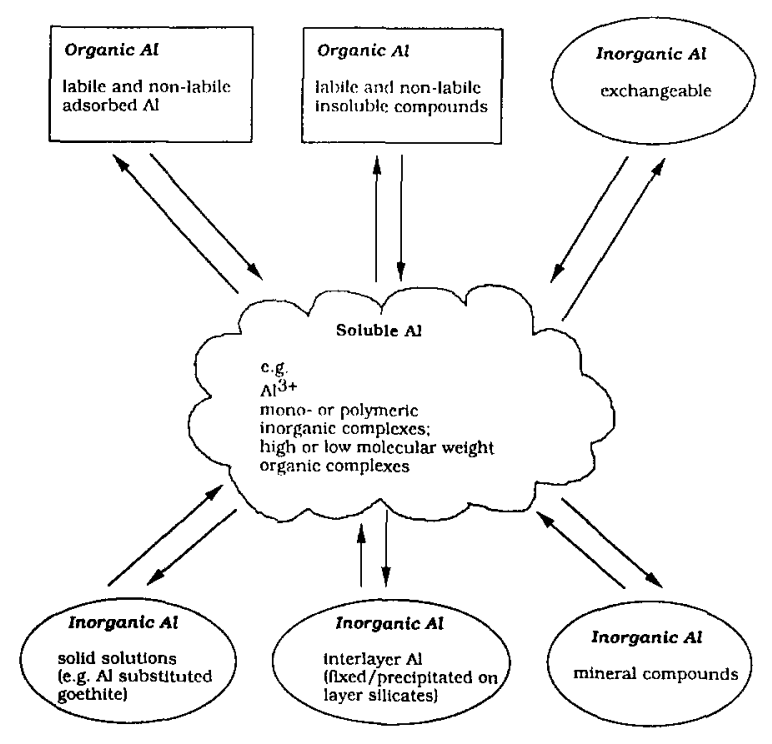

Fig. 1. The forms of aluminium in acidic soils.

This review will consider where $\mathrm{Al}$ is coming from (sources), where it is going to (sinks) and what can happen along the road in between. I shall briefly consider the different types of solid forms of Al, particularly from a kinetic point of view and discuss models that have been developed to predict $\mathrm{Al}$ release from individual forms. I shall then discuss models that have been developed to predict $\mathrm{Al}$ quantities in solution in open soil systems where more than one source or sink for $\mathrm{Al}$ is considered. Finally, I shall discuss a conceptual model for predicting the retention and release of $\mathrm{Al}$ from all soil sources.

\section{Mineral forms of Al}

The mineral forms of $\mathrm{Al}$ that may exist in soils include hydrous oxides (e.g. gibbsite), alumino-silicates (e.g. feldspars, kaolinite, imogolite), sulphates (e.g. jurbanite) and phosphates such as variscite (see reviews by Dixon and Weed, 1989; Hemingway and Sposito, 1989a; Lindsay, 1979; Lindsay and Walthall, 1989).

The factors influencing the dissolution and precipitation of Al-containing minerals have been reviewed by Davis and Hayes (1986), Hochella and White (1990) and Ritchie (1994) and are summarised in Figure 2. The driving force for the dissolution or precipitation of a compound is the amount of free energy that is lost in the process. The free energy is composed of the standard free energy of the reaction (as defined by equilibrium thermodynamics) plus the free energy of

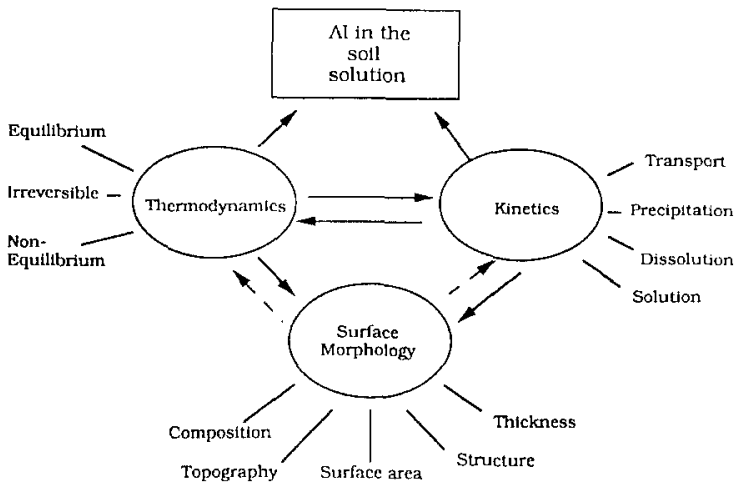

Fig. 2. Factors influencing the dissolution and precipitation of aluminium containing minerals (Ritchie, 1994).

precipitate growth and nucleation (for precipitation) or the free energy of the breakdown of the lattice structure of the solid phase (for dissolution). Until recently, it has been assumed that the standard free energy of the reaction is the major driving force for dissolution or precipitation and hence equilibrium thermodynamics can be used to describe the extent of the reaction. However, the limited success of this approach has led to consideration of the importance of other sources of free energy loss, related to the kinetics of the reaction. Thermodynamics defines the potential for a reaction to occur and the minimum amount of work required for the reaction (Lewis and Randall, 1923). Kinetics, as affected by surface morphology and transport of reactants and products to and from a surface, determines how long the reaction takes to reach equilibrium.

The major factors that influence the rate of dissolution of minerals in soils appear to be $\mathrm{pH}$ and the presence of ions that react with the dissolving or precipitating surface. For example, the release of $\mathrm{Al}$ by the dissolution of $\mathrm{Al}$ oxides and kaolinite is a function of $\mathrm{pH}$ in the range where $\mathrm{H}^{+}$ions are adsorbed by the clay surface and reaches a maximum when no more $\mathrm{H}^{+}$ ions can be adsorbed $(\mathrm{pH}<3.5$; Stumm and Wieland, 1990; Wieland and Stumm, 1992). In contrast, the dissolution of montmorillonite has been found to increase almost linearly as pH decreases from 4 to 2 (Furrer et al., 1991). The rate of $\mathrm{Al}$ release is enhanced by adsorption of ions that react with only one metal centre in the crystal lattice (Stumm and Wieland, 1990) and retarded by surface complexation of soluble ions that react with more than one metal centre or by precipitation coating the surface and blocking potential dissolution sites (Furrer et al., 1991). Aggregation of clay particles can also slow down dissolution rates because $\mathrm{H}^{+}$ 
ions have to diffuse through an aggregate before being adsorbed at a reactive site (Furrer et al., 1991). Precipitation is mainly affected by interfacial surface energies as manifested by the difference in nucleation rates for discrete particles and for recipitation on existing surfaces (Ritchie, 1994).

The modelling of dissolution and precipitation is reviewed by Hochella and White (1990) and Ritchie (1994). In soil research, predicting aluminium solubility from mineral dissolution and precipitation has only been attempted using equilibrium thermodynamics, and has had limited success. Manley et al. (1987) found that their estimate of $\mathrm{Al}^{3+}$ in the soil solutions of the $\mathrm{A}, \mathrm{B}$ and $\mathrm{C}$ horizons of three soils could not be explained by equilibrium thermodynamics when they considered the minerals kaolinite, gibbsite, hallyosite, allophane, imogolite and amorphous $\mathrm{Al}(\mathrm{OH})_{3}$. In the topsoil, $\mathrm{Al}^{3+}$ was considered to be mainly complexed with organic ligands which resulted in these soil solutions being undersaturated with respect to gibbsite. Conyers (1990) also found that soluble Al in 25 soils from New South Wales could not be explained by equilibrium with either quartz and kaolinite or with gibbsite. $\mathrm{pH}$ and $\mathrm{Al}^{3+}$ in three of the soils were related via the equation $\mathrm{pAl}=2.95 \mathrm{pH}-8.1$. This was considered "close to the theoretical slope of 3.0, and the intercept corresponds with a sub-crystalline $\mathrm{Al}(\mathrm{OH})_{3}$ ". However, a change in slope from 3.0 to 2.95 can cause an error of approximately $30 \%$ in the estimate of $\mathrm{Al}^{3+}$ which, at $\mathrm{pH} \leq 4.2$, could be sufficient to identify incorrectly the soil as containing toxic quantities of $\mathrm{Al}$ for plant growth (Ritchie, 1994). Conyers (1990) postulated that soluble $\mathrm{Al}$ was more likely to be controlled by organic matter in horizons with organic pools that were not already Al-saturated. Gibson et al. (1992) also found that an oxisol contained soluble $\mathrm{Al}^{3+}$ "close to saturation with respect to gibbsite". However, the difference between the data and the solubility line for gibbsite indicated that predicting $\mathrm{Al}^{3+}$ from gibbsite would result in a large overestimate of the actual $\mathrm{Al}^{3+}$ (e.g. at $\mathrm{pH} 4.214$, gibbsite is in equilibrium with $25 \mu \mathrm{M} \mathrm{Al}^{3+}$ whereas the actual data indicated $\mathrm{Al}^{3+}$ was approximately $14 \mu M$ ). At $\mathrm{pH} \leq 4.2$ such overestimates can led to erroneous decisions about whether a soil contains sufficient $\mathrm{Al}$ to be toxic to plants (Ritchie, 1994).

The above results, along with the factors discussed by Ritchie (1994), all demonstrate that equilibrium thermodynamics cannot be used in models to predict soluble $\mathrm{Al}^{3+}$ in soil solutions in the short (daysmonths) to medium (months-years) term.

\section{Exchangeable and interlayer Al}

Exchangeable $\mathrm{Al}$ (i.e. bound to soil surfaces by electrostatic bonds) is a major form of $\mathrm{Al}$ in soils and has been a frequent focus of research, particularly in relation to acidic soils. This work has been extensively reviewed (e.g. Adams, 1984; Ritchie, 1989; Thomas and Hargrove, 1984; Zelazny and Jardine, 1989) and hence will not be discussed further here.

The modelling of exchange reactions has centred on the estimate of selectivity coefficients for the exchange between two cations onto phylosilicates and has been the subject of much research since 1850 (see reviews by Bolt, 1982; Harter, 1986; Sposito, 1981; White and Zelazny, 1986). The application of these models to soils has met with limited success, particularly as the charge on the cation increases. The lack of suitability has been attributed to the lower ionic strengths and solid phase cation ratios in soils, diffuse layer effects and to solid phase activity coefficients for cations being $<1$ (White and Zelazny, 1986).

The kinetics of ion exchange were reviewed by Sparks (1989). He concluded that the mineralogical composition was a major influence on rates of ion exchange varying from a few seconds to days. Assuming an equivalent number of charged sites, exchange is usually rapid onto external surface sites (e.g. kaolinite) or internal sites of highly expanded 2:1 layer silicates (e.g. illite and smectite). On the other hand, exchange is much slower when access to internal sites is hindered by ion swelling (e.g. vermiculite) or by the presence of selectively adsorbed cations (e. g. $\mathrm{K}^{+}$and $\mathrm{NH}_{4}^{+}$adsorbed onto micas). Accordingly, Jardine et al. (1985a) found that $\mathrm{Al}$ exchange with $\mathrm{Ca}$ on kaolinite and smectite was relatively rapid $(<100$ and 500 min, respectively). If clays are compared on a basis of equal surface area, however, smectites adsorb Al faster than kaolinite because the high surface charge density of the smectites overrides the effect of accessibility of exchange sites (Walker et al., 1988). In contrast, vermiculite did not adsorb Al faster than kaolinite, in the same study, even though it had a slightly higher charge

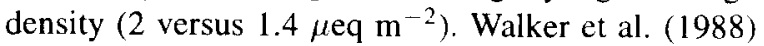
suggested that the ease of access to sites is far greater in kaolinite than in vermiculite, whereas the difference in site accessibility between kaolinite and smectite is much smaller.

The formation of interlayer $\mathrm{Al}$ has been recognised for many years and has been reviewed by several workers (Barnhisel and Bertsch, 1989; Hsu, 1989; Huang, 1988; Rich, 1968; Zelazny and Jardine, 1989). I shall 
only summarise the major findings here. Interlayer $\mathrm{Al}$ is present as polymeric, hydrolysed $\mathrm{Al}$ that is fixed by the mineral as well as possibly occurring as a precipitate. The extent to which $\mathrm{Al}$ is fixed depends upon the $\mathrm{Al} / \mathrm{OH}$ ratio, the presence of ions that may compete for $\mathrm{Al}$ (and hence decrease hydrolysis), and the amount and origin of charge (i.e. expansibility) on the mineral (Zelazny and Jardine, 1989). The extent of polymerisation of interlayer $\mathrm{Al}$ tends to be in the order kaolinite < smectite < vermiculite < illite (Jardine et al., 1985 a, b; Zelazny and Jardine, 1989). The fixation of polymeric hydrolysed $\mathrm{Al}$ may occur randomly over the planar surface or along the edges depending on the interlayer spacing of the mineral and Al saturation of the system. Smectites tend to adsorb more interlayer $\mathrm{Al}$ than vermiculite because of their lower charge density and higher expansibility. The large size and charge of interlayer $\mathrm{Al}$ tends to make it non-exchangeable but not unreactive, because it can protonate or deprotonate in response to changes in $\mathrm{pH}$. For smectites, as the $\mathrm{Al}$ ratio of the fixed polymeric $\mathrm{Al}$ approaches 3.0 , the solubility of aluminium hydroxides may be exceeded and precipitation can occur. If the suspensions are left to age, gibbsite can form and destabilise the interlayer, resulting in the release of the gibbsite.

This behaviour is not observed in the case of vermiculites, possibly because vermiculite tends to adsorb hydroxy-Al that is far less polymerised (because of its higher charge density) and hence less likely to form a precipitate. The $\mathrm{Al}: \mathrm{OH}$ ratio of interlayer $\mathrm{Al}$ in kaolinite is usually $\leq 2.4$ and therefore conversion of $\mathrm{Al}$ hydroxide precipitates to gibbsite is not favoured. The Al precipitates on kaolinite are only stable when present in small amounts (Turner and Brydon, 1967).

The kinetics of interlayer $\mathrm{Al}$ adsorption and desorption has not received much attention, partly because some researchers have not delineated interlayer $\mathrm{Al}$ from exchangeable Al. Jardine et al. (1985a, b) recognised that the adsorption of interlayer $\mathrm{Al}(>1000 \mathrm{~min}$ ) at $\mathrm{pH} 4.3$ onto kaolinite was a much slower process than exchange ( $\leq 100 \mathrm{~min}$ ) and involved hydrolysis and polymerisation. At $\mathrm{pH} \mathrm{4}$, however, adsorption of interlayer $\mathrm{Al}$ did not occur apparently because of the lack of hydroxyl ions.

The slow kinetics of interlayer $\mathrm{Al}$ adsorption is due to factors that affect exchange (e.g. structure, $\mathrm{OH}: \mathrm{Al}$ ratio) as well as changes in solution forms with time and experimental conditions (time period studied, batch vs. flow studies, \% Al saturation of exchange sites). When the Al added to a clay suspension is far in excess of the cation exchange capacity, CEC (e.g.
Turner and Brydon, 1967), the reactions occurring may not be representative of those occurring in soils where $\% \mathrm{Al}$ saturation is commonly lower, even under acidic conditions (Hodges and Zelazny, 1983; Ritchie, 1989), and would include not only exchange and interlayer $\mathrm{Al}$ adsorption but also precipitation of $\mathrm{Al}$ compounds. Hence it is difficult to deduce the kinetics of interlayer $\mathrm{Al}$ adsorption from such studies.

Part of the slowness of interlayer $\mathrm{Al}$ adsorption could be due to changes in the Al forms in solution with time as observed by Hodges and Zelazny (1983). In such a situation, a slow rate of interlayer adsorption is not necessarily due to the slowness of one reaction but could be due to the quantity of soluble reactive species being decreased by hydrolysis and polymerisation in solution or the adsorption rate being a net value for the adsorption of several different species.

\section{Organic Al}

The amount and variation of $\mathrm{Al}^{3+}$ with $\mathrm{pH}$ in soils cannot always be explained by mineral solubility or exchange onto inorganic surfaces (Bloom et al., 1979; Cronan et al., 1986; Robarge and Johnson, 1992), and hence it has been hypothesised that $\mathrm{Al}$ bound by organic matter controlled soluble $\mathrm{Al}^{3+}$. The reactions of $\mathrm{Al}$ with organic matter have been reviewed in detail elsewhere (Huang, 1988; Ritchie, 1989; Stevenson and Vance, 1989) and are considered only briefly here. This paper discusses how the forms of organic Al may be modelled and the kinetics of release of organic $\mathrm{Al}$.

Aluminium may react with both soluble and insoluble organic matter which is either high molecular weight $(>1000)$ organic material of indeterminate origin or discrete low molecular weight $(<1000)$ organic molecules of known formula and structure (e.g. citric acid). The reactive part of indeterminate organic matter is commonly referred to as humic substances (MacCarthy et al., 1990). The solid humic substances may be $25-67 \%$ of total soil organic matter (Stevenson, 1986; Tipping and Hurley, 1988) and contain carboxyl groups that dissociate at $\mathrm{pH}<7$ and are approximately equivalent to the CEC of organic matter. Other, weakly acidic groups dissociate at $\mathrm{pH}>7$ and are mainly carboxyl or phenolic hydroxyl groups. The total acidity of humic substances is considered to be the acidity titratable to $\mathrm{pH} \approx 11.00$ (Tipping and Hurley, 1988). Solid humic substances may specifically adsorb $\mathrm{Al}$ (as an inner-sphere complex) or retain it by electrostatic forces only, i.e. exchangeable or outer-sphere com- 
plex (Stevenson and Vance, 1989). The extent of inner sphere complexation will depend on the intrinsic binding constants of the carboxyl groups, the proportion of mono- and multi-dentate adsorption sites, electrostatic interactions between adjacent negatively charged sites, $\mathrm{pH}$, ionic strength and the presence of competing cations (Tipping and Hurley, 1988). The extent of outer sphere complexation will depend on the net amount and density of charge on the humic material remaining after specific adsorption, the presence of competing cations, $\mathrm{pH}$ and ionic strength (Zelazny and Jardine, 1989).

Little is known about the amount of discrete low molecular weight organic molecules in the solid phase. Theoretically, anions such as oxalate form reasonably insoluble complexes with cations. In practice, however, these forms may precipitate out of solution but only remain stable for short time periods because of their role as microbial substrates. In addition, the indeterminate soluble humic substances can form insoluble compounds, but this is not widely considered in the literature. With respect to modelling, such precipitation reactions may be handled in the same way as precipitation of inorganic forms of $\mathrm{Al}$ (e.g. gibbsite) once solubility constants have been estimated. Tipping and Woof (1990) attempted to predict the precipitation/dissolution of humic substances by developing a relationship between solubility and the net electric charge on the humic molecule. As pointed out by the authors, such an approach is limited because the dependence on net electric charge results in all potentially soluble humic substances being released simultaneously rather than through time. An approach that included a constant to describe the equilibrium solubility of an Al-humate precipitate may have avoided this complication but would not account for the effect of kinetics on the attainment of a steady-state equilibrium.

Soluble organic matter includes humic substances that can complex and apparently detoxify Al. These include humic and fulvic acids and discrete, low molecular weight organic molecules such as citric acid (Nordstrom and May, 1989; Ritchie, 1989; Stevenson and Vance 1989).

The modelling of interactions between metals and humic substances has concentrated mainly on reactions in solution as affected by $\mathrm{pH}$, ionic strength and properties of the humic molecules (e.g. Driscoll, 1989; Marinsky and Ephraim, 1986; Stevenson and Vance, 1989; and references therein). The models of Tipping and co-workers are an exception because they recognise explicitly the existence of both soluble and solid humic substances (e.g. Tipping and Hurley, 1988). The different approaches to modelling have been discussed by Bartschat et al. (1992), Dzombak et al. (1986) and Tipping et al. (1988). The models vary in their theoretical basis and their purpose. Some models seek to explain the chemical behaviour of humic substances in detail (e.g. Marinsky and Ephraim, 1986), whereas others are more concerned with developing pragmatic models that can be incorporated into ecosystem models for predicting cation cycling but at the same time are mechanistic in approach (Barstchat et al., 1992; Tipping and Hurley, 1992; Young and Bache, 1985). The theoretical basis of the models varies according to whether the humic molecule is considered to have one type of functional group or several different binding ligands that are discrete in nature or form a continuum (e.g. a log normal distribution of binding constants). Despite differences in approach, there appears to be a consensus of opinion that humic substances may be considered to behave as impenetrable, spherical oligoelectrolytes. The assumption that humic substances are impenetrable may be valid at low $\mathrm{pH}$ values but not be relevant at higher $\mathrm{pH}$ for humic acids (Ritchie and Posner, 1982). A detailed discussion of the different models is not within the scope of this review. Hence, I shall only refer to models that consider both solid and soluble humic substances and which could be incorporated in overall cation cycling models.

Cronan et al. (1986) developed a simple model which related $\mathrm{Al}^{3+}$ in two organic horizons from a forest soil to $\mathrm{pH}, \mathrm{CuCl}_{2}$ extractable $\mathrm{Al}$ and acidity titratable to $\mathrm{pH} 7$ :

$$
\mathrm{pAl}^{3+}=\mathrm{b}(\mathrm{pH})+\mathrm{c}
$$

where $\mathrm{b}=1.05 \times($ bound $\mathrm{Al}$ ratio $)+0.345$ and $\mathrm{c}=$ $(5.67 \times$ bound $\mathrm{Al}$ ratio $)+3.879$. The ratio of $\mathrm{CuCl}_{2}-$ extractable $\mathrm{Al}$ and titratable acidity was considered to represent $\mathrm{Al}$ bound by organic matter (bound $\mathrm{Al}$ ratio). The model predicted $\mathrm{pAl}^{3+}$ in thirteen samples from six watersheds better than an exchange model. The applicability of this approach may be limited, however, because $\mathrm{CuCl}_{2}$ has been observed to extract interlayer or recently precipitated Al (Ritchie, 1989).

An equilibrium model that predicts proton and metal binding by soluble and insoluble humic substances as affected by $\mathrm{pH}$, ionic strength and electrostatic interactions between adjacent sites has been developed by Tipping and Hurley (1992). It considers the formation of mono- or bi-dentate inner-sphere complexes as well as electrostatic attraction of cations in both the solid and soluble phases (Tipping and Hurley, 1988). 
The charged sites on the humic substances are divided into eight distinct proton binding groups (each with a discrete proton dissociation constant) which were postulated to combine to form 12 possible combinations for bi-dentate complexing. The extent of metal binding is estimated from $\mathrm{pH}$ and the amount of free metal ion using mass and charge balance equations. The model does not account for size heterogeneity and assumes that protons and metals bind at the same sites. Other workers have presented evidence that protons tend to be associated with low molecular weight material, while metal ions are apparently preferentially adsorbed at sites on larger molecules (Bartschat et al., 1992).

In order to link the modelling of soluble and insoluble forms of humic substances, Tipping and Woof $(1990,1991)$ conceptualised solid humic substances to consist of a mobile or potentially mobile component and an immobile component. The mobile component is distributed between the solution and solid phases. They assume that the mobile humic substances can be divided into fractions with similar ion binding properties and molecular weight but different hydrophobicity, The metal binding behaviour of the mobile humic substances as considered to be independent of the phase it is in. They preferred to describe the solubility of humic substances in terms of adsorption/desorption reactions rather than precipitation/dissolution (Tipping and Woof, 1990), because the former approach could predict changes in soluble humic substances with time, whereas the latter model released all potentially soluble humic substances in one dissolution event. As would be expected, including the release of $\mathrm{H}^{+}$by plants (due to $\mathrm{Ca}^{2+}$ uptake) in their model, decreased $\mathrm{pH}$ and increased $\left[\mathrm{Al}^{3+}\right]$ and lowered the net humic charge.

The kinetics of cation release from humic substances has been reviewed by Sparks (1989), but there have been few studies that include Al. Tipping and Woof (1990) found that the release of Al from solid humic substances was slower in the presence of an initially higher concentration of $\mathrm{Ca}$. Their model predicted that a change in the $\mathrm{H}^{+}$concentration of an incoming solution from $\mathrm{pH} 4$ to 5 over one year resulted in the $\mathrm{pH}$ of the soil solution taking $10-100 \mathrm{yrs}$ to reach a steady state. The model flushes a soil volume with successive aliquots of incoming rain and estimates the surface and solution concentration of $\mathrm{Al}$ after equilibration of the rain with the solid phase. Hence, the time to reach a steady state with respect to $\mathrm{Al}$ can be estimated if the volume of soil, moisture holding capacity, residence time and annual rainfall are known. In contrast, Cronan et al. (1986) observed that soluble $\left[\mathrm{Al}^{3+}\right]$ was desorbed or adsorbed from organic horizons of two forest soils within $5 \mathrm{~min}$, and Bloom et al. (1979) found that the time taken for soluble $\mathrm{Al}$ to reach a constant value varied from 2 to $35 \mathrm{~d}$ or more. Bunzl et al. (1976) found that metal cations (other than $\mathrm{Al}$ ) were exchanged from peat very rapidly (10-30 s). Jardine et al. (1985a) found that Al adsorbed onto Ca-saturated peat reached a maximum after $8 \mathrm{~d}$. An inflection in the curve of soluble $\mathrm{Al}$ vs. time approximately $2 \mathrm{~d}$ after $\mathrm{Al}$ was added to the peat suggests that there may be more than one group of sites reacting with the $\mathrm{Al}$ as postulated by Tipping and Woof (1991).

\section{Modelling soluble Al}

Models developed to predict the extent of acidification due to acidic precipitation consider atmospheric, hydrological, geochemical and biogeochemical processes to different extents and over different time periods. As in any modelling procedures, a balance has to be found between being conceptually correct about the numerous processes that may be occurring and creating an unwieldy model that requires numerous measurements as input and contains so many parameters that many combinations of their values can produce the same predictions. The models will be discussed only in relation to their approach to predicting soluble $\mathrm{Al}^{3+}$.

In most models, the parameters in equations describing exchange and dissolution or weathering rates are chosen by calibration techniques, i.e. the parameter values are varied until the model output is similar to experimental data from catchment studies. The drawbacks to such an approach are recognised by the researchers involved and have to be lived with until our knowledge of these reactions has increased. One way to decrease the errors arising from the calibration of parameters is to have as many sets of data as possible so that the parameter values are constrained to values that can predict more than one set of data (Cosby et al., 1986).

Comparisons between models can be limited if they have been designed to predict changes in Al soil chemistry over different time periods. Within the timescale of a model, however, it needs to be recognised that different processes may act over different time periods; for example, exchange occurs very rapidly (hoursdays), whereas mineral weathering is slow (monthsyears). In addition, the choice of timescale is dependent on the predictions required. If we are interested in plant growth in acidic soils within the growing season, 
then a daily timescale is important. However, a yearly timescale would probably be more than adequate if we are concerned with predicting the time required between lime applications.

Three of the most commonly used models for predicting acidity have been reviewed by Eary et al. (1989). The ILWAS model (Gherini et al., 1985) is the most process-oriented and considers the smallest time intervals (daily); the MAGIC model (Cosby et al., 1985) considers the same geochemical processes in less detail than ILWAS, because it is aimed at predicting longer-term changes (several years). Both models estimate soluble $\mathrm{Al}$ by recognising speciation in solution (only ILWAS includes organic-Al complexing, exchange onto clay surfaces and dissolution of $\mathrm{Al}$ hydroxides). The kinetics of these reactions are not modelled explicitly in either model, but the effect of kinetics on $\mathrm{Al}$ in solution is recognised to the extent that the rate of base cation weathering is included and thereby could affect $\mathrm{Al}$ exchange and $\mathrm{Al}$ hydroxide dissolution. Cosby et al. (1986) found that the predictions made by MAGIC were the most sensitive to changes in the parameters set to describe base cation weathering, $\mathrm{CO}_{2}$ equilibria, aluminium solubility and the exchange of base cations with Al. However, the values of the parameter used to describe base cation weathering rates varied from $4.0 \times 10^{-10}-1.24 \times$ $10^{-9}$ meq $\mathrm{m}^{-2} \mathrm{~s}^{-1}$ which is several orders of magnitude faster than what is observed in both laboratory experiments and in the field for aluminium silicates. Neither model considers $\mathrm{Al}$ dissolution from silicates or Al bound to solid organic matter.

Models have also been developed in which the geochemical processes are based on the conservation of alkalinity and hence they do not predict explicitly the quantity of $\mathrm{Al}$ in solution (Nikolaidis, 1988; Schnoor et al., 1984). The third model reviewed by Eary et al. (1989) is ETD (Nikolaidis, 1988) and falls into this category. Such models are of limited use in predicting soluble Al as the latter can only be implicitly estimated by assuming that it is controlled by $\mathrm{pH}$ alone. This has not been found to be the case (Driscoll, 1989).

Furrer et al. $(1989,1990)$ have developed a steadystate model in which the chemical processes may be designated as fast (thermodynamic equilibrium is achieved), slow (kinetically controlled), and very slow (essentially static). The model is as comprehensive as ILWAS in describing chemical processes but is more flexible because any process may be designated to any time period. Hence it is possible to recognise the dissolution of Al-containing minerals as slow process- es. However, its ability to predict $\mathrm{H}^{+}$and $\mathrm{Al}^{3+}$ fluxes in an actual catchment has yet to be tested. Sensitivity analyses of a simplified hypothetical system (Furrer et al., 1989) indicates that soluble $\mathrm{Al}^{3+}$ is more sensitive to the velocity of water flow through the system than the rate of dissolution of an aluminium hydroxide or the influx of $\mathrm{H}^{+}$. If the complexity of the system was increased (from an aluminium hydroxide dissolving in the presence of an influx of $\mathrm{H}_{2} \mathrm{SO}_{4}$ ) to simulate a soil environment (Furrer et al., 1990), the outcome appeared to rely on the structure of the soil system defined and the choice of parameter values. The model structure now included processes that produced $\mathrm{H}^{+}$(e.g. biomass decomposition, nitrification, ammonification, atmospheric deposition) and consumed $\mathrm{H}^{+}$(e.g. decomposition of organic acids produced by biomass decomposition and base cation production from mineral dissolution). In contrast, the dissolution of $\mathrm{Al}(\mathrm{OH})_{3}$ in the soil environment was considered to be fast and hence was described by equilibrium thermodynamics rather than dissolution kinetics as in the previous example. This had the effect of increasing soluble $\mathrm{Al}^{3+}$ at equivalent $\mathrm{pH}$ values. In another hypothetical soil system, an organic soil was simulated by decreasing the rate of decomposition of organic acids which had the net effect of decreasing $\mathrm{pH}$ and increasing soluble $\mathrm{Al}^{3+}$. The structure of the model did not allow for the commonly observed decrease in the production and decomposition of biomass with decreasing $\mathrm{pH}$ which would have counterbalanced the $\mathrm{pH}$ decrease caused by the lower decomposition of organic acids.

Even though existing acidification models are becoming more sophisticated by introducing more processes and are solving algorithms more efficiently (e.g. Furrer et al., 1990), they are still curve fitting exercises because the values of parameters are selected to fit available data. In addition, there is still a need for better recognition of the importance of organic reactions as a sink for $\mathrm{Al}^{3+}$, the kinetics of $\mathrm{Al}$-mineral dissolution and the dependence of kinetic processes on several factors.

None of the models discussed explicitly allows for organic reactions of $\mathrm{Al}$ in the solid phase. It is becoming increasingly apparent that soluble $\mathrm{Al}^{3+}$ in topsoils and organic horizons cannot be adequately explained by mineral dissolution or inorganic exchange reactions in the short term (Cronan et al., 1986; Mulder et al., 1989). The reactions of organic matter and Al could be implicitly considered in exchange processes, but this represents only one type of solid organic-Al inter- 
action. It also assumes that exchange reactions onto organic matter occur at the same rate as onto phyllosilicates. This was not found to be the case by Jardine et al. (1985a). The concepts of Al bound to solid organic matter similar to those espoused by Tipping and coworkers (e.g. Tipping and Woof, 1990) need to be incorporated into future models.

Furrer et al. (1989) are the only workers so far who appear to have attempted to predict dissolution of $\mathrm{Al}$ hydroxides using a rate equation. However, they only included the effect of $\mathrm{pH}$ on the dissolution rate process and did not consider other factors (such as organic acids, extent of saturation) as discussed by Ritchie (1994). In addition, the biogeochemical processes that affect $\mathrm{pH}$ (and hence $\mathrm{Al}^{3+}$ ) are considered to be time dependent (in those models that recognise such processes), but the equations used to describe them are fairly limited in their inclusion of factors that affect the kinetics of the processes. For example, ILWAS expresses the rates of sulphate reduction, litter decomposition and nitrification only as a function of the concentration of reactants, whereas the rates will also be very sensitive to changes in $\mathrm{pH}$, temperature and soil moisture content because of the involvement of soil microorganisms in the processes. In addition, the decomposition of organic matter could be decreased by complexing with Al (Furrer et al., 1989) which would tend to decrease $\mathrm{pH}$.

It is well recognised that equating the prediction of models with laboratory or field results may only be as accurate as the methods of sampling and measurement and the design of experiments. With respect to acidic soils, sometimes insufficient measurements are made to test a model thoroughly, e.g. only $\mathrm{pH}$ is measured. In cases when $\mathrm{Al}$ is measured, the extraction technique may not be capable of distinguishing between different forms of solid $\mathrm{Al}$ and therefore may overestimate the quantity of $\mathrm{Al}$ in the form under investigation. For example, acid extracts have been used for organically bound Al (Tipping and Woof, 1991) even though acids will also extract inorganic Al. Lanthanum chloride has been used to extract interlayer Al by some workers, whereas others have used it for separating organically bound Al (Ritchie, 1989). Similarly, $\mathrm{CuCl}_{2}$ may not only extract organic $\mathrm{Al}$ but also recently-precipitated $\mathrm{Al}$ (Ritchie, 1989). In laboratory experiments, prewashing of soils may release readily soluble $\mathrm{Al}$ and the timescale of experiments may not be relevant to the timescale of observations made in the field or predicted by models. The problems in estimating different forms

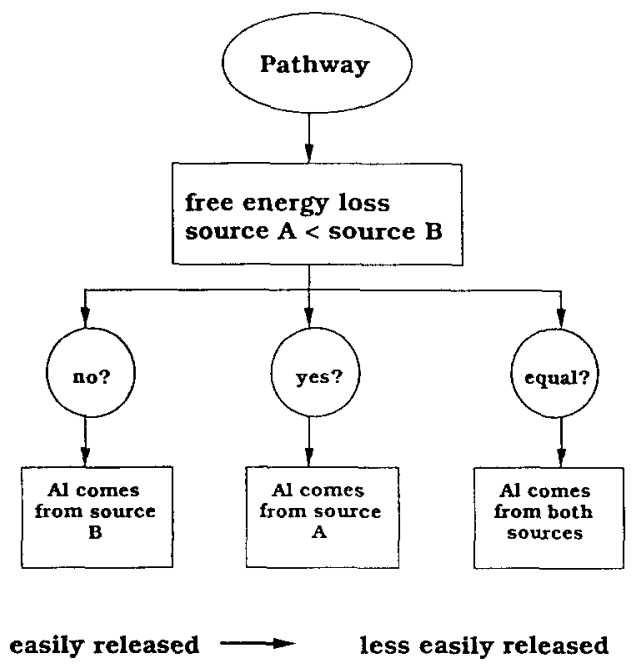

Fig. 3. The release of $\mathrm{Al}$ according to the Law of Successive Reactions.

of soluble $\mathrm{Al}$ by various analytical methods have been extensively reviewed by Bloom and Erich (1989).

\section{A conceptual basis for predicting retention and release of $\mathrm{Al}$ from solid sources}

The previous discussion and Ritchie (1994) have highlighted the drawbacks from considering only equilibrium thermodynamics when attempting to predict soluble $\mathrm{Al}$. In theory, equilibrium dynamics states that the most stable solid form is that which has the lowest free energy and so the formation of a solid which resulted in the largest loss of free energy would be favoured. In practice, we observe the presence of many solid forms in soils that are unstable with respect to equilibrium thermodynamics which suggests that the actual reactions which occur involve small losses of free energy.

With respect to mineral dissolution, the above dichotomy has been explained by the Law of Successive Reactions (LSR), which observes that compounds precipitate/dissolve in a sequence according to the amount of free energy lost, beginning with the compound that results in the minimum loss in free energy i.e. in the case of precipitation, the most soluble compound precipitates first, followed by a sequence of less and less soluble compounds (Hemingway, 1982; Sposito, 1989a). The observation could be applied to all possible solid sources of $\mathrm{Al}$ (Fig. 3) indicating that $\mathrm{Al}$ release into solution is a sequence of events in which the most easily released $\mathrm{Al}$ is released first. The source 


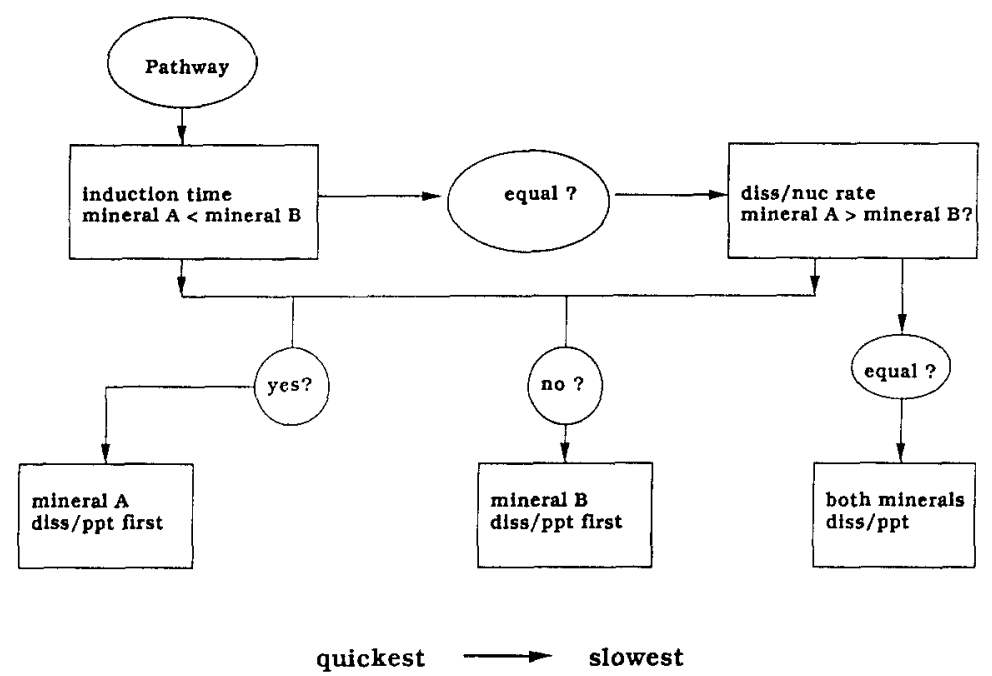

Fig. 4. The kinetic rule of stages.

of $\mathrm{Al}$ at a particular moment will depend on the factors affecting Al dissolution from minerals (i.e. the ultimate long term source that supplies $\mathrm{Al}$ for other sinks such as exchangeable $\mathrm{Al}$ ); the relative size and $\mathrm{Al}$ affinity of other sinks (i.e. Al sinks that could act as short term sources) and the factors that affect $\mathrm{Al}$ retention by them.

The source of $\mathrm{Al}$ will also depend on the current status of the sequence defined by the LSR in relation to our timescale of interest. This conceptual approach to elucidating the source of $\mathrm{Al}$ in soil acknowledges the dynamic nature of soil; the possibility of more than one source; and that the source can change with time. However, it cannot completely describe the effect of kinetics on the sequence of events and there is an underlying assumption that the most thermodynamically stable source will be reached within the timescale of interest.

The kinetics of release and retention can be accommodated by considering the Kinetic Rule of Stages (Van Straten et al., 1984) which predicts that the most kinetically labile minerals will precipitate first (Fig. 4). Kinetic lability is a function of the induction time (time to reach a steady state) and the rate of nucleation or dissolution. Minerals dissolve in a sequence beginning with the compounds with the shortest induction times, followed by those with the quickest nucleation rates. Similarly, this rule does not have to apply to minerals alone, but may be used in combination with the LSR to conceptualise the release and retention of $\mathrm{Al}$ from all possible soil sources (Fig. 5). The driving force for

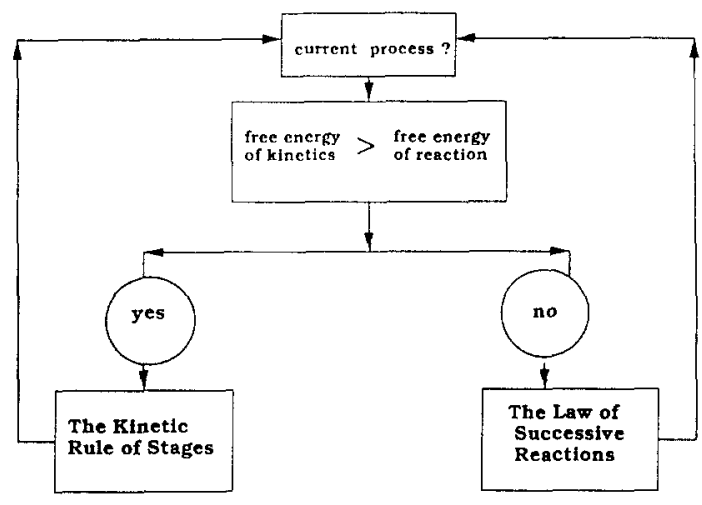

Fig. 5. A conceptual basis for predicting soluble $\mathrm{Al}$ in soils.

a process to occur is the amount of free energy that is lost. At each point in time, within a sequence of events, we need to compare the free energy of kinetics with the free energy of the reaction to elucidate the source or sink of $\mathrm{Al}$ and whether kinetics or thermodynamics is controlling the sequence of events. The sequence will continue until the free energy of the system reaches a minimum, which may take minutes or millenia.

\section{Conclusions}

Soluble Al results from a sequence of events that involves the stepwise loss of free energy, where the smallest loss occurs first and may be kinetic or thermodynamic in nature. Our understanding of Al chemistry 
in soils has perhaps been limited by our lack of appreciation that there was no single, specific form of solid $\mathrm{Al}$ that controls soluble Al even within the same soil type. Aluminium in the soil solution is a function of both thermodynamics and kinetics. The ultimate source may be Al-containing minerals, but the pathway of the $\mathrm{Al}$ before it reaches the solution may involve retention and release by several other solid-phase sinks.

The importance of different solid forms of $\mathrm{Al}$ in controlling the amount in solution will vary with the timescale of interest. For example, exchangeable $\mathrm{Al}$ may be important in the short term (days) but, over longer periods (months), its ability to maintain soluble Al will depend on the amount of, and speed with which other sources (e.g. interlayer or organically bound $\mathrm{Al}$ ) can replenish exchangeable forms. In turn, the ability of interlayer and organic forms of $\mathrm{Al}$ to restore exchangeable $\mathrm{Al}$ in the longer term (years) will depend on the kinetics of mineral dissolution.

At this stage, it is difficult to establish which factor is the most limiting in predicting soluble $\mathrm{Al}$ accurately: our ability to measure forms of $\mathrm{Al}$ and $\mathrm{pH}$ in soils or our ability to identify and model the major processes controlling soluble Al. It is important, therefore, that long term field monitoring of acidic properties should continue but only if the extraction and analytical techniques are chosen carefully to reflect the current standing of our knowledge. It is no less important that models should evolve further to include, in particular, the different forms of organically bound $\mathrm{Al}$ and kinetic consideration of $\mathrm{Al}$ release. The choice of model depends on the timescale of interest as related to the extent of detail required. As the timescale of interest decreases, the more likelihood that processes need to be modelled in greater detail and by mechanistic rather than curve fitting approaches.

\section{References}

Adams F 1984 Soil Acidity and Liming. American Agronomy Society, Madison, WI, USA. 380 p.

Barnhisel R I and Bertsch P M 1989 Chlorites and hydroxyinterlayed vermiculite and smectite. In Minerals in Soil Environments. Eds. J B Dixon and S B Weed. pp 729-788. Soil Science Society of America, Madison, WI, USA.

Bartschat B, Cabaniss S E and Morel F M M 1992 Oligoelectrolyte model for cation binding by humic substances. Environ. Sci. Technol, 26, 286-294.

Bloom P R and Erich M S 1989 The quantitation of aqueous aluminum. In The Environmental Chemistry of Aluminum. Ed. G Sposito. pp 1-27. CRC Press, Boca Raton FL, USA.

Bloom P R, Mc Bride M B and Weaver R M 1979 Aluminum organic matter in acid soils: buffering and solution aluminum activity. Soil Sci. Soc. Am. J. 43, 688-693.
Bolt G H 1982 Soil Chemistry. B. Physico-chemical models. Elsevier, Amsterdam, The Netherlands.

Bunzl K, Schmidt W and Sansoni B 1976 Kinetics of ion exchange in soil organic matter. IV. Adsorption and desorption of $\mathrm{Pb}^{2+}$, $\mathrm{Cu}^{2+}, \mathrm{Cd}^{2+} \mathrm{Zn}^{2+}$ and $\mathrm{Ca}^{2+}$ by peat. J. Soil Sci. $27,32-41$.

Conyers M R 1990 The control of aluminium solubility in some acidic Australian soils. J. Soil Sci. 41, 147-156.

Cosby B J, Homberger G M and Galloway J N 1985 Modelling the effects of acid deposition: assessment of a lumped parameter model of soil water and streamwater chemistry. Water Resour. Res. 21, 51-63.

Cosby B J, Hornberger G M, Rastetter E B, Galloway J N and Wright R F 1986 Estimating catchment water quality response to acid deposition using mathernatical models of soil ion exchange processes. Geoderma 38, 77-95.

Cronan C S, Walker W J and Bloom P R 1986 Predicting aqueous aluminum concentrations in natural waters. Nature 324, 140-143.

Davies J A and Hayes K F 1986 Geochemical Processes of Mineral Surfaces. American Chemical Society, Washinton, D.C., USA.

Dixon J B and Weed S B 1989 Minerals in the Soil Environment. Soil Sci. Soc. Am., Madison,, WI, USA.

Driscoll C T 1989 The chemistry of aluminum in surface waters. In The Environmental Chemistry of Aluminum. Ed. G Sposito. pp 241-277. CRC Press, Boca Raton, FL, USA.

Dzombak D A, Fish W and Morel F M M 1986 Metal-humate interactions. 1. Discrete ligand and continuous distribution models Environ. Sci. Technol. 20, 669-675.

Eary L E, Jenne E A, Vail L W and Girvin D C 1989 Numerical models for predicting watershed acidification. Environ. Contam. Toxicol. 18, 29-53.

Einstein A 1979 Autobiographical Notes. Open Court Pub. Co, Chicago, USA.

Furrer G, Westall J and Sollins P 1989 The study of soil chemistry through quasi-steady-state models: 1. Mathematical definition of model. Geochim. Cosmochim. Acta 53, 595-601.

Furrer G, Sollins P and Westall J 1990 The study of soil chemistry through quasi-steady-state models: 2 . Acidity of soil solution. Geochim. Cosmochim. Acta 54, 2363-2374.

Furrer G, Zysset M, Charlet L and Schindler P W 1991 Mobilisation and fixation of aluminium in soils. Metal Compounds Environ. Life 4, 89-97.

Gherini S A, Mok L, Hudson R J M, Davis G F, Chen C W and Goldstein R A 1985 The ILWAS model; formulation and application. Water Air Soil Pollut. 26, 425-460.

Gibson J A E, Willett I R and Bond W J 1992 The effects of sulphate and fluoride on the sorption of aluminium by an oxisol. J. Soil Sci. 43, 429-439.

Harter R P 1986 Adsorption Phenomena. Van Nostrand Reinhold, New York, USA.

Hemingway B S 1982 Gibbs free energies of formation for bayerite, nordstrandite, $\mathrm{Al}(\mathrm{OH})^{2+}$ and $\mathrm{Al}(\mathrm{OH})^{2+}$, aluminum mobility and the formation of bauxites and laterites. Adv. Phys. Geochem. 2. 283-316.

Hemingway B S and Sposito G 1989 Inorganic aluminum bearing solid phases. In The Environmental Chemistry of Aluminum. Ed. G Sposito. pp 55-86. CRC Press, Boca Raton, FL, USA.

Hochella M F and White A F 1990 Mineral-Water Interface Geochemistry. Mineralogical Society of America, Washington, DC, USA.

Hodges S C and Zelazny L W 1983 Interactions of dilute, hydrolysed aluminum solutions with clays, peat and resin. Soil Sci. Soc. Am J. 47, 206-212. 
Hsu P H 1989 Aluminum oxides and oxyhydroxides. In Minerals in the Soil Environment. Eds. J B Dixon and S B Weed. pp 331-378. Soil Science Society of America, Madison, WI, USA.

Huang P M 1988 Ionic factors affecting aluminum transformations and the impact on soil and environmental sciences. Adv. Soil Sci. $8,1-78$.

Jardine P M, Zelazny L W and Parker J C 1985a Mechanism of aluminum adsorption on clay minerals and peat. Soil Sci. Soc. Am. J. 49, 862-867.

Jardine P M, Parker J C and Zelazny L W 1985b Kinetics and mechanisms of aluminum adsorption on kaolinite using a twosite non-equilibrium transport model. Soil Sci. Soc. Am. J. 49, $867-873$.

Lewis G N and Randall M 1923 Thermodynamics. Mc Graw-Hill, New York, USA. 653 p.

Lindsay W L 1979 Chemical Equilibria in Soils. John Wiley, New York, USA. 449 p.

Lindsay W L and Walthall P M 1989 The solubility of aluminum in soils. In The Environmental Chemistry of Aluminum. Ed. G Sposito. pp 221-240. CRC Press, Boca Raton, FL, USA.

MacCarthy P, Clapp C E, Malcolm R L and Bloom P R 1990 Humic Substances in Soil and Crop Sciences. Selected Readings. American Society of Agronomy, Madison, USA.

Manley E P, Chesworth W and Evans L J 1987 The solution chemistry of podzolic soils from the eastern Canadian shield: a thermodynamic interpretation of the mineral phases controlling soluble $\mathrm{Al}^{3+}$ and $\mathrm{H}_{4} \mathrm{SiO}_{4}$. J. Soil Sci. 38, 39-51.

Marinsky J A and Ephraim J 1986 A unified physicochemical description of the protonation and metal ion complexation of natural and organic acids (humic and fulvic acids). 1. Analysis of the influence of polyelectrolyte properties on protonation equilibria in ionic media: fundamental concepts. Environ. Sci. Technol 20, 349-356.

Mulder J, Van Breemen N and Eijck H C 1989 Depletion of soil aluminium by acid deposition and implications for acid neutralisation. Nature 337, 247-249.

Nikolaidis N 1988 A generalised soft water acidification model. Water Resour. Res. 24, 1983-1996.

Nordstrom D K and May H M 1989 Aqueous equilibrium data for mononuclear aluminum species. In The Environmental Chemistry of Aluminium. Ed. G Sposito. pp 29-54. CRC Press, Boca Raton, FL, USA

Rich C I 1968 Hydoxy interlayers in expansible layer silicates. Clays Clay Miner. 16, 15-30.

Ritchie G S P 1994 The role of dissolution and precipitation of minerals controlling soluble aluminium in acidic soils. Adv. Agron. $53,47-83$.

Ritchie G S P 1989 The chemical behaviour of aluminium, hydrogen and manganese. In Soil Acidity and Plant Growth. Ed. A D Robson. pp 1-60. Academic Press, New York, USA.

Ritchie G S P and Posner A M 1982 The effect of pH and metal binding on the transport properties of humic acids. J. Soil Sci. 33, 233-247.

Robarge W P and Johnson D W 1992 The effects of acidic deposition on forested soils. Adv. Agron. 47, 1-83.

Schnoor J L, Palmer W D Jr and Glass G E 1984 Modelling impacts of acid precipitation for northeastern Minnesota. In Modelling of Total Acid Precipitation Impacts. Ed. J L Schnoor. pp 155-173. Butterworths, London, UK.

Sparks D L 1989 Kinetics of Soil Processes. Academic Press, San Diego, CA, USA. 210 p.

Sposito G 1989a The Environmental Chemistry of Aluminum. CRC Press, Boca Raton, FL, USA. 317 p.
Sposito G 1989b The Chemistry of Soils. Oxford University Press, New York, USA.

Sposito G 1981 The Thermodynamics of Soil Solutions. Oxford University Press, New York.

Steefel C I, Van Capellan P, Nagy K L and Lasaga A C 1990 Modelling water-rock interactions in the surficial environment: the role of precursors, nucleation, and Ostwald ripening. Chem. Geol. $84,322-325$.

Stevenson F J 1986 Cycle of Soil, Carbon, Nitrogen, Phosphorus, Sulphur, Micronutrients. John Wiley, New York, USA

Stevenson F J and Vance G F 1989 Naturally occurring aluminumorganic complexes. In The Environmental Chemistry of Aluminum. Ed. G Sposito. pp 117-146. CRC Press, Boca Raton, FL, USA.

Stumm E and Wieland E 1990 Dissolution of oxide and silicate minerals: rates depend on surface speciation. In Aquatic Chemical Kinetics. Ed. W Stumm. pp 367-400. John Wiley, New York, USA.

Thomas G W and Hargrove W L 1984 The chemistry of soil acidity. In Soil Acidity and Liming. Ed. F Adams. pp 3-56. American Society of Agronomy, Madison, WI.

Tipping E and Hurley M A 1988 A model of solid-solution interactions in acid organic soils, based on the complexation properties of humic substances. J. Soil Sci. 39, 505-519.

Tipping E and Hurley M A 1992 A unifying model of cation binding by humic substances. Geochim. Cosmochim. Acta 56, 36273641 .

Tipping E and Woof C 1990 Humic substances in acid organic soils: modelling their release to the soil solution in terms of humic charge. J. Soil Sci. 41, 573-586.

Tipping E and Woof C 1991 The distribution of humic substances between the solid and aqueous phases of acid organic soils; a description based on humic heterogeneity and charge dependent sorption equilibria. J. Soil Sci. 42, 437-448.

Tipping E, Backes C A and Hurley M A 1988 The complexation of protons, aluminium and calcium by aquatic humic substances: a model incorporating binding site heterogeneity and macroionic effects. Water Res. 22, 597-611.

Turner R C and Brydon J E 1967 Effect of length of time of reaction on some properties of suspensions of Arizona bentonite, illite, and kaolinite in which aluminum hydroxide is precipitated. Soil Sci. 103, 111-117.

Van Straten H A, Holtkamp B T W and de Bruyn P L 1984 Precipitation from supersaturated aluminate solutions. I. Nucleation and growth of solid phases at room temperature. J. Coll. Int. Sci. 98 , 342-362.

Walker W J, Cronan C S and Patterson H H 1988 A kinetic study of aluminum adsorption by aluminosilicate clay minerals. Geochem. Cosmochim. Acta 52, 55-62.

Wieland E and Stumm W 1992 Dissolution kinetics of kaolinte in acidic aqueous solutions at $25^{\circ} \mathrm{C}$. Geochim. Cosmochim. Acta $56,3339-3355$

White G N and Zelazny L W 1986 Charge properties of soil colloids. In Soil Physical Chemistry. Ed. D L Sparks.pp 39-81. CRC Press Boca Raton, FL, USA.

Young S D and Bache B W 1985 Aluminium-organic complexation formation constants and a speciation model for the soil solution J. Soil Sci. 36, 261-269.

Zelazny L W and Jardine P M 1989 Surface reactions of aqueous aluminum species. In The Environmental Chemistry of Aluminum. Ed. G Sposito. pp 147-184. CRC Press, Boca Raton, FL, USA. 